\title{
Simulation of a collector using waste heat energy in a solar chimney power plant system
}

\author{
Azeemuddin, H. H. Al-Kayiem \& S. I. Gilani \\ Mechanical Engineering Department, \\ Universiti Teknologi PETRONAS, Malaysia
}

\begin{abstract}
Rare techniques have been proposed for twenty four hour operation of a solar chimney power plant (SCPP). In this study, another technique is suggested by utilizing waste heat energy in the form of flue gases flow in conduits within the solar collector. The process of the heat and fluid flow within the collector were simulated using ANSYS software. The predicted performance and enhancement of the collector are presented and discussed. The results show a significant increase in the overall performance of the solar chimney power plant. At $1000 \mathrm{~W} / \mathrm{m}^{2}$ solar radiation, the collector temperature rise is from 19 to $23 \mathrm{~K}$, the updraft velocity is increased from $15.6 \mathrm{~m} / \mathrm{s}$ to $17.1 \mathrm{~m} / \mathrm{s}$, the power output increased from $50.1 \mathrm{~kW}$ to $66.1 \mathrm{~kW}$ and the efficiency is improved from $0.116 \%$ to $0.144 \%$. Although the technique contributes to the performance enhancement of the SCPP, it also contributes to the reduction of global warming by reduction of the exhausted flue gases temperature.
\end{abstract}

Keywords: air heater, gas turbine, solar chimney power, waste heat energy.

\section{Introduction}

The solar chimney power plant (SCPP) is truly a renewable technology. The technology works on simple laws of physics. There are three main components namely, collector (also called air heater), turbine and chimney. The collector is the main engine in this system. The air collector traps the heat energy from solar irradiation and as a product due to the absorbed heat and buoyancy effect it increases the kinetic energy of the air enough to drive the turbine. The turbine is placed in the system where it can extract maximum air kinetic energy usually at the base of the chimney. The chimney plays an important role in creating a 
suction effect at the collector inlet. Fresh air is sucked in and the cycle is repeated. The main advantage of this technology is that it is durable and requires less maintenance. And the main disadvantage of this system is that it cannot operate at night. But many studies have suggested the operation at night by utilizing water filled bags that absorbs heat during day and releases at night. In this paper a proposed model is discussed to utilize waste heat from a nearby gas turbine power plant with the solar chimney power plant. The purpose of this study is to let the power plant work during night hours and to increase in the output power at day time.

The main components of SCPP system are shown in fig. 1. The collector resembles the greenhouse; the turbine can be linked with the windmill and chimney to the traditional ventilation purposes inside building and industries. This makes SCPP system quite a familiar technology.

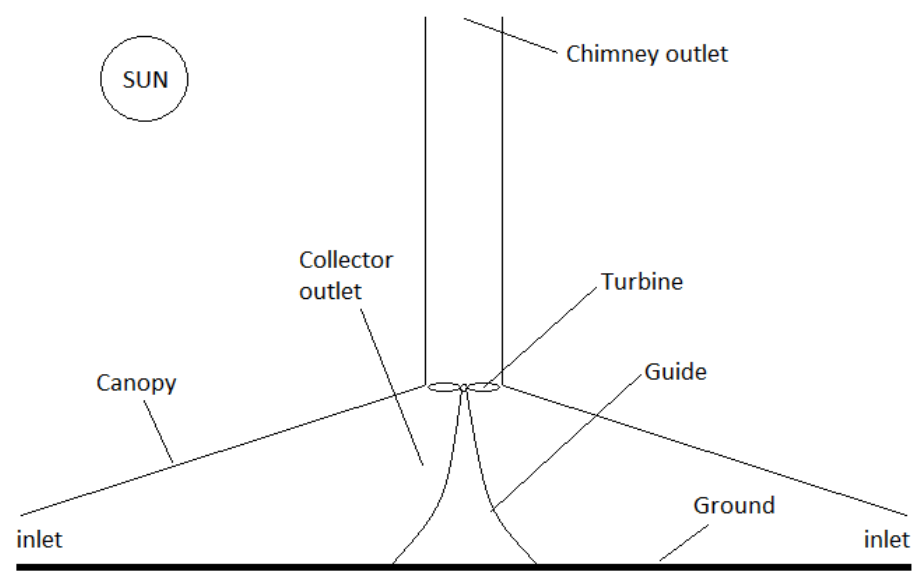

Figure 1: $\quad$ Schematic diagram of the solar chimney power plant.

\section{SCPP enhancement and 24 hour operation}

\subsection{Previous works}

Many studies proposed for continues working of the SCPP during night hours. A detailed numerical analysis was carried out by Roozbeh et al. [1], showing with increasing solar radiation values, the power increases. Simulation with energy storage layer for different solar radiations was carried out by Tingzhen et al. [2], which resulted in heat loss from the storage medium increasing with an increase in solar radiations. According to Dos Santos Bernardes et al. [3], the power output can be increased by increasing chimney height, collector area and transmittance. Another study by Jiakuan et al. [4], show that power output of power generating system increases with global solar radiation intensity, collector area and chimney height. It also concluded that the larger the chimney height, the 
greater would be the driving force in air. The use of water storage system in collector was presented by Kreetz [5], his study indicated a continuous day and night operation of the solar chimney power plant. Al-Kayiem et al. [6] have reported simulation results of inclined SGPP integrated with flue gas as thermal back up. The simulation was validated by comparing with experimental measurements. They claimed that the inlet flue temperature is considerably influencing the system performance. A review paper on the SGPP enhancement was published by Chikere et al. [7], in which, they proposed the use of the flue gas as waste to energy in double inclined SGPP.

\subsection{Proposed design}

In this study, in order to utilize the waste heat from a gas turbine power plant, some design modification has been made in the existing classical solar chimney power plant. Channels were introduced in this proposed technique, which were hollow rectangular in shape. The channel proceed from the collector inlet and ends at the collector outlet with variable height according to collector canopy. The placement of channels is determined by dividing the circular shaped collector by a number of channels. Fig. 2(a) describes the orientation of four channels. Waste heat in the form of exhaust gases are transferred to the channel by means of pipe illustrated in fig. 2(a). The pipe section inside the channel has holes, the gases through these holes spread inside the whole channel. At the collector outlet section of the channel, these gases are allowed to release from top into the chimney as shown in fig. 2(b).

The exhaust gases inside the channels experience a heat transfer mechanism to the channels walls through convection. Second heat transfer takes place within the channel walls through conduction. Third takes place by means of convection to the collector air. This collector air reaching the chimney inlet has increased its temperature and velocity. Thus, an increase in kinetic energy results in an increase in output power.

\subsection{Advantages of proposed concept}

Using the waste heat with SCPP system, the plant would be able to deliver power during nights, when it would be running only on exhaust gases. Power output of would be consistent during the cloudy weather or in raining condition. Overall efficiency of the plant would increase.

\subsection{Channel design specifications}

In this study, Manzanares prototype (first prototype located in Spain) of SCPP was used as the reference plant. The height of the channels were taken in correspondence with the prototype collector canopy height. The material and dimensions are discussed in table 1 . The reason to use carbon steel is because it can withstand high temperatures typically ranging between $1425^{\circ} \mathrm{C}$ to $1540^{\circ} \mathrm{C}$. 


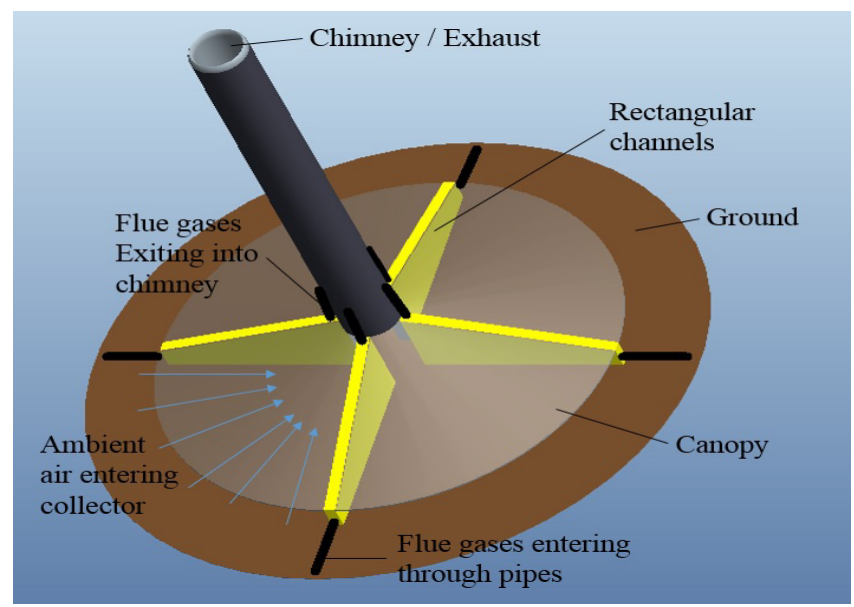

(a)

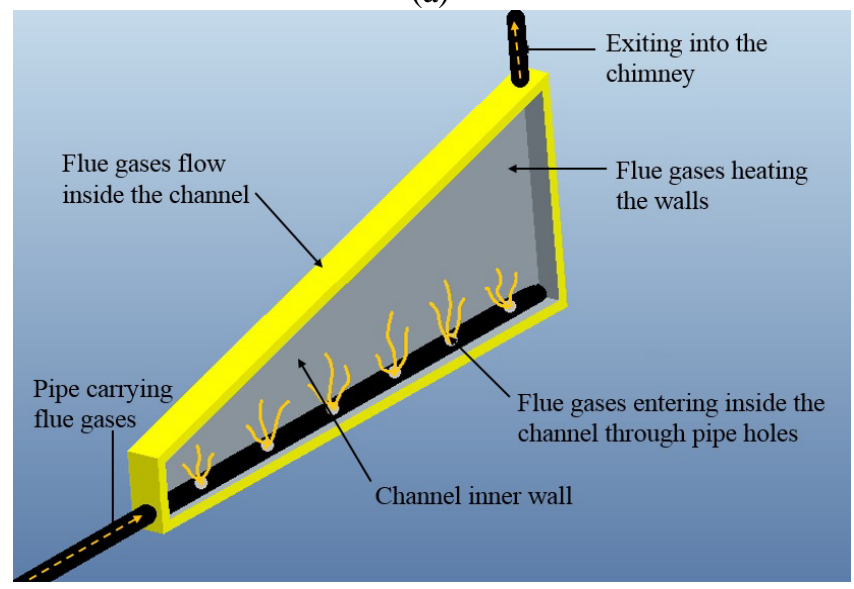

(b)

Figure 2: (a) Three dimensional model for the proposed technique. (b) Schematic showing operation inside the channel.

Table 1: $\quad$ Channel specifications.

\begin{tabular}{|l|c|}
\hline \multicolumn{1}{|c|}{ Parameter } & Value \\
\hline Material & AISI 1010 Carbon Steel \\
\hline Height at Inlet & $2 \mathrm{~m}$ \\
\hline Height at Collector Outlet & $6 \mathrm{~m}$ \\
\hline Wall Thickness & $0.015 \mathrm{~m}$ \\
\hline Inner Width & $0.17 \mathrm{~m}$ \\
\hline Length & $117 \mathrm{~m}$ \\
\hline
\end{tabular}




\section{Heat transfer evaluation procedure}

In order to simulate the heat transfer mechanism from the exhaust gases to the collector air through the walls of the channels, ANSYS Fluent CFD software (version 14) was used. Keeping Manzanzres SCPP prototype as reference, i.e. using the plant dimensions, a geometry consisting of two channels, canopy section and ground, was modelled as shown in fig. 3(a) with a symmetry boundary condition in the middle. The reason for modelling two channels only is that other sections would yield the same results. Two fluid domains were created namely, a) exhaust gases domain, b) collector air domain. For heat transfer analysis, the collector air was assumed to be an ideal gas. A close-up view of all components mentioned above is presented in fig. 3(b). It is important to mention

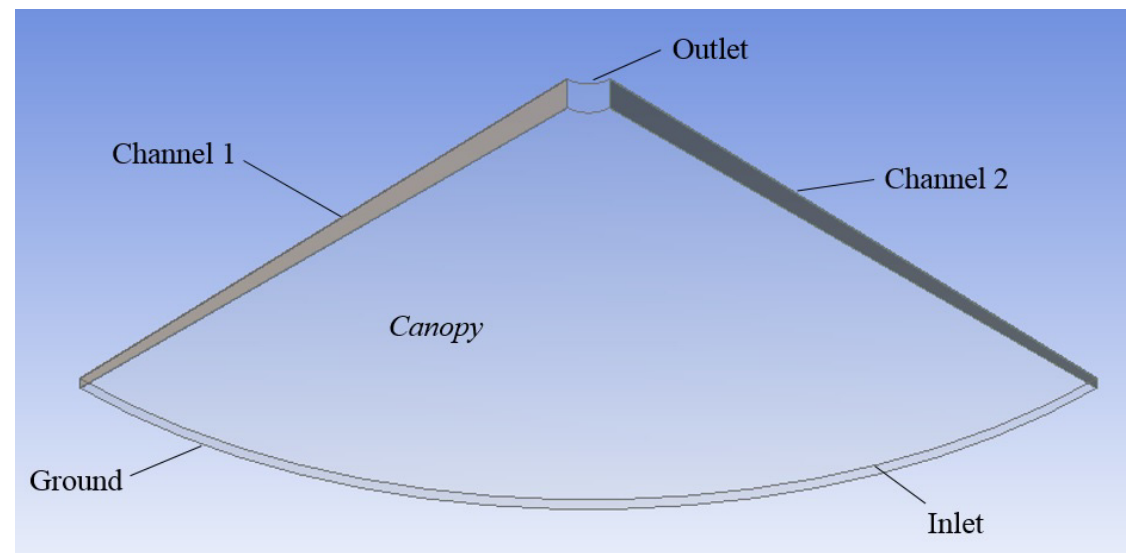

(a)

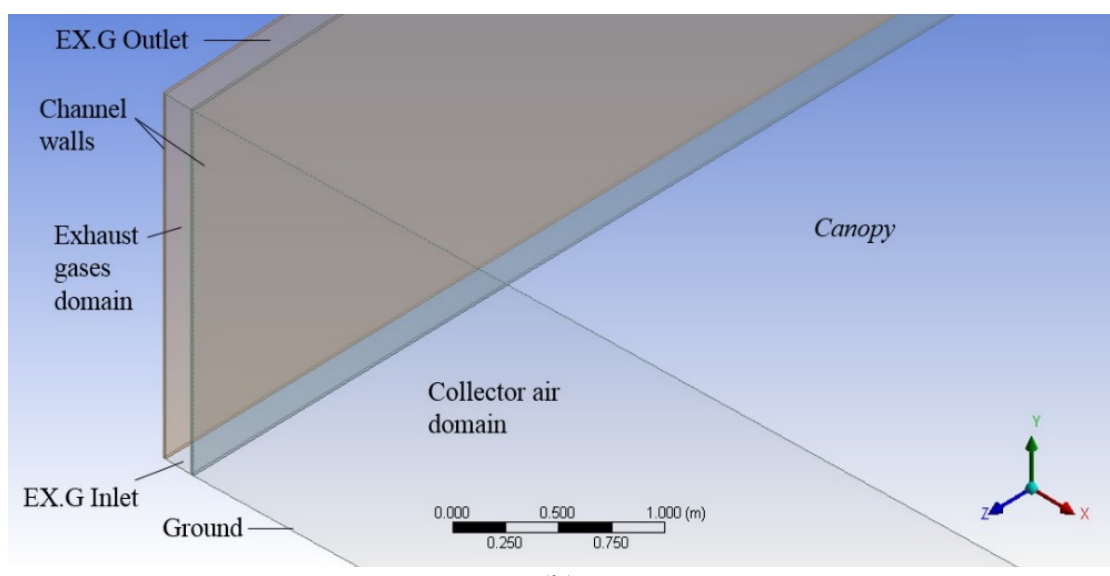

(b)

Figure 3: (a) Schematic of modelled collector geometry with two channels.

(b) Zoomed view of geometry components. 
that the lower face of exhaust gases domain is the inlet abbreviated in the fig. 3(b) as 'EX.G Inlet' and upper one is the outlet abbreviated as 'EX.G Outlet', this is to make analysis simple.

Depending upon the hardware limitations of the computer, the problem was just limited to the collector modelling only. A steady state analysis was considered for this simulation.

\subsection{Assumptions}

The main assumptions used in the channel design are mentioned below.

- The exhaust gases properties are evaluated at the gas turbine exit temperature.

- The mass flow of the gases are equally distributed among the number of channels considered.

The exhaust gases from the turbine exit are assumed to be at the inlet of the channels keeping in view the mass flow rate equally divided by the number of channels considered.

\subsection{Boundary conditions}

Table 2 shows boundary conditions for collector, flow of air and exhaust gases at their inlets and outlets.

Table 2: $\quad$ Boundary conditions.

\begin{tabular}{|l|c|}
\hline Component & Condition \\
\hline Collector Inlet & Velocity Inlet \\
\hline Collector Outlet & Pressure Outlet \\
\hline Canopy & $\begin{array}{c}\text { Constant temperature wall (mean } \\
\text { temperature of component) } \\
\text { Ground }\end{array}$ \\
\hline Exhaust Gases Inlet & temperature wall (mean \\
Exhaust Gases Outlet & Pressure Outlet \\
\hline
\end{tabular}

\subsection{ANSYS fluent governing equations}

SCPP system is an axisymmetric structure, requires three-dimensional cylindrical coordinate system. The governing equations include continuity equation, momentum equation, and energy conservation equation. For the steady state compressible flow, the continuity equation is defined as

$$
\frac{1}{r} \frac{\partial}{\partial \theta}(\rho u)+\frac{1}{r} \frac{\partial}{\partial r}(r \rho v)+\frac{\partial}{\partial z}(\rho w)=0
$$

Universally, the general partial differential equation is the following 


$$
\begin{aligned}
& \frac{1}{r} \frac{\partial}{\partial \theta}(\rho u \phi)+\frac{1}{r} \frac{\partial}{\partial r}(r \rho v \phi)+\frac{\partial}{\partial z}(\rho w \phi) \\
& =\frac{1}{r} \frac{\partial}{\partial \theta}\left(\frac{\Gamma_{\phi}}{r} \frac{\partial \phi}{\partial \theta}\right)+\frac{1}{r} \frac{\partial}{\partial r}\left(\Gamma_{\phi} r \frac{\partial \phi}{\partial r}\right)+\frac{\partial}{\partial z}\left(\Gamma_{\phi} \frac{\partial \phi}{\partial z}\right)+S_{\phi}
\end{aligned}
$$

where, $r, \theta$, and $z$ are cylindrical coordinates; $\rho$ is the air density; $\varphi$ is the universal variable, it can be circumferential velocity $u$, radial velocity, $v$ or axial velocity, $w$, kinetic energy of turbulence, $K$ and rate of dissipation $\varepsilon$ and temperature $T$ respectively; $\Gamma_{\varphi}$ is diffusion coefficient; $S_{\varphi}$ is source item. When $\varphi$ is determined, $\Gamma$ and $S$ will have relative given values or expressions respectively [8].

\subsection{Meshing and mesh quality}

The meshing technique used in the study is 'multizone technique'. The structured hexahedral mesh was generated in ANSYS Meshing module. Fig. 4 shows the mesh in each domain. Exhaust gas domain and collector air domain is separated by the solid zone of channel wall. Multizone technique is quite useful and applicable when there are different zones. The mesh quality was determined by the aspect ratio, orthogonal quality and skewness. Three meshes were generated to check the solution mesh independency. Table 3 shows the quality of the mesh used in the present study. Although three mesh generation computed nearly same results such as the outlet temperature $320.8761 \mathrm{~K}, 320.8884 \mathrm{~K}$ and $320.4253 \mathrm{~K}$ for mesh 1 , mesh 2 and mesh 3 respectively. So, the selected mesh was the lowest one 'mesh 1 ' so as to reduce hardware cost and simulation time.

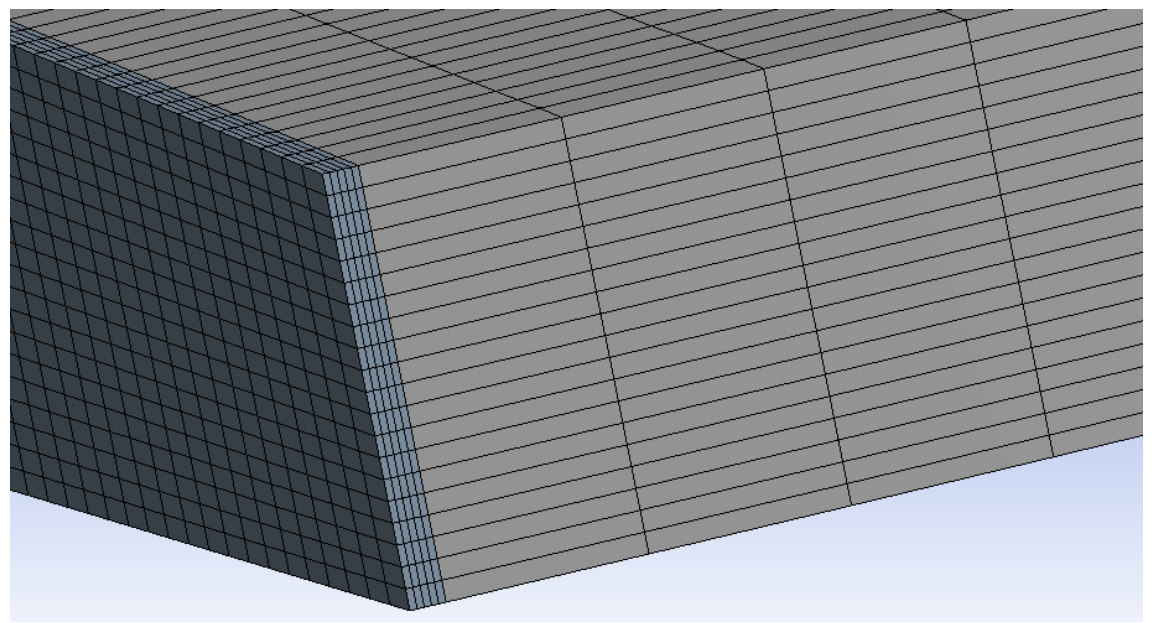

Figure 4: Hexahedral mesh generation on exhaust gas and collector air domain. 
Table 3: $\quad$ Mesh independency and mesh quality.

\begin{tabular}{|l|c|c|c|c|}
\hline & Elements & Aspect ratio & $\begin{array}{c}\text { Orthogonal } \\
\text { quality }\end{array}$ & Skewness \\
\hline Mesh 1 & 735000 & 9.8377 & 0.99 & $5.618 \mathrm{e}-2$ \\
\hline Mesh 2 & 925000 & 9.3762 & 0.99 & $7.630 \mathrm{e}-2$ \\
\hline Mesh 3 & 1231200 & 9.8973 & 0.99 & $5.597 \mathrm{e}-2$ \\
\hline
\end{tabular}

\subsection{Linkage to the mathematical model of the SCPP system}

A mathematical model was developed prior to this heat transfer simulation in which classical SCPP model was simulated with weather data conditions for a Madrid city. Madrid is very much closer to Manzanares, Spain. It was an assumption that the weather conditions remain same. The results were validated with the Manzanares prototype i.e. at $1000 \mathrm{~W} / \mathrm{m}^{2}$ solar irradiation, the power output was calculated to be $50.1 \mathrm{~kW}$ which was quit promising [9]. After the validation, the effects of exhaust gases heat transfer were observed with this simulation. This is why this simulation deals a simple heat transfer problem. The boundary conditions inputs for canopy, ground and collector inlet were taken from the simulated results of the mathematical model. The data inputs for exhaust gases was taken from a SIEMENS catalog [10] of gas turbines containing data described in table 4.

Table 4: $\quad$ Exhaust gases specifications.

\begin{tabular}{|l|c|}
\hline \multicolumn{1}{|c|}{ Parameter } & Value \\
\hline Fuel type & Natural gas \\
\hline $\begin{array}{l}\text { Mass flow for each channel (4 } \\
\text { channels) }\end{array}$ & $24.475(\mathrm{~kg} / \mathrm{s})$ \\
\hline Temperature of the exhaust gas & $643.15(\mathrm{~K})$ \\
\hline PROPERTIES (at exhaust gas temp.) & - \\
\hline Dynamic viscosity & $2.9992 \mathrm{e}-5\left(\mathrm{~N} . \mathrm{s} / \mathrm{m}^{2}\right)$ \\
\hline Specific heat & $1126.8(\mathrm{~J} / \mathrm{kg} . \mathrm{K})$ \\
\hline Thermal conductivity & $0.04909(\mathrm{~W} / \mathrm{m} . \mathrm{K})$ \\
\hline Density & $0.53136\left(\mathrm{~kg} / \mathrm{m}^{3}\right)$ \\
\hline
\end{tabular}

\section{Results and discussions}

Two simulations were carried out in this study to compare the effects of using exhaust gases on the system. One was to simulate using solar effects (solar mode) and second with solar as well as channels (hybrid mode). Fig. 5 demonstrates the improvement made in the power output, updraft velocity and collector temperature rise in SCPP system at $1000 \mathrm{~W} / \mathrm{m}^{2}$ solar irradiation with and without waste heat energy input to the system. 


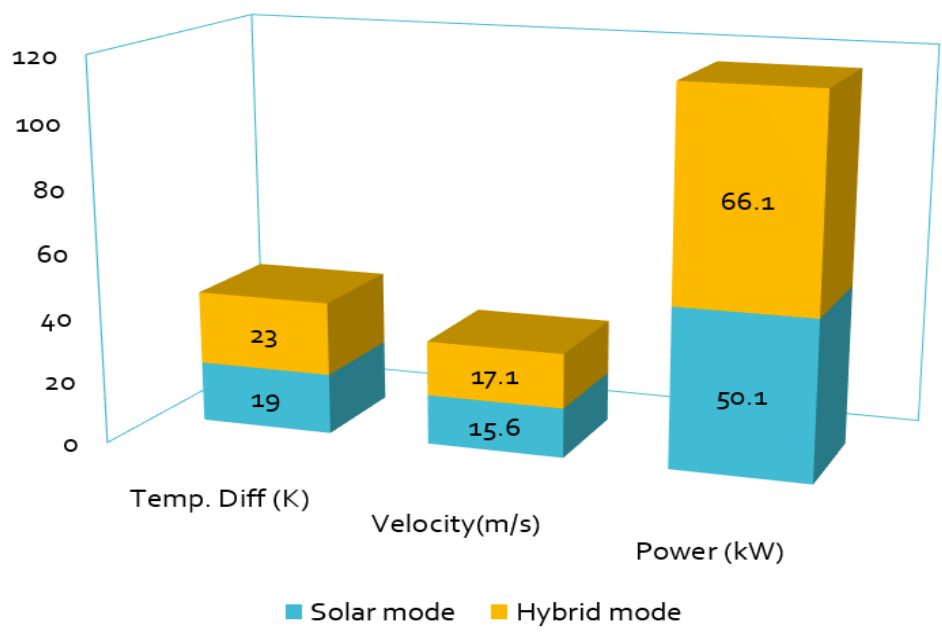

Figure 5: Effects of waste heat energy on various parameters of SCPP system.

During the early hours, the plant is capable of running on exhaust gases as represented by fig. 6 .

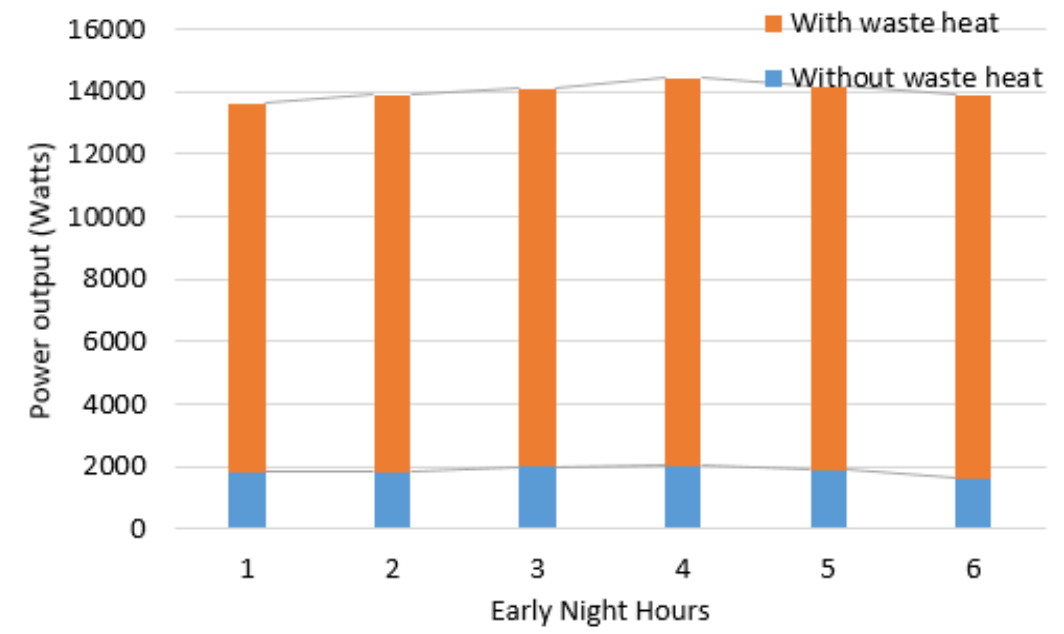

Figure 6: $\quad$ Power output during early night hours.

This night operation of the plant proves that the plant is capable to deliver improved power output during the daytime because both solar and exhaust effects would be contributing in adding heat to the collector air. This also enables the overall efficiency of the plant to increase. At $1000 \mathrm{~W} / \mathrm{m}^{2}$, overall efficiencies are compared in fig. 7. 


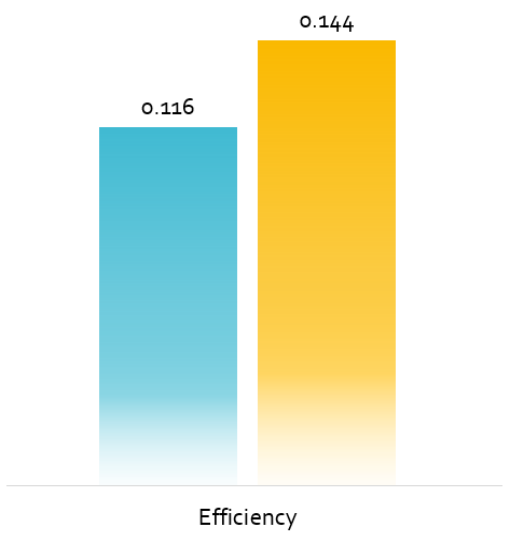

Figure 7: Overall thermal efficiency of the SCPP system.

The hybrid mode thermal efficiency is calculated as

$$
\eta=\frac{P_{\text {out }}}{\left[Q_{\text {solar }}+Q_{\text {wasteheat }}\right]}
$$

where, $P_{\text {out }}$ is the combined power output from the plant, $Q_{\text {solar }}$ is the heat input from the solar irradiation and $Q_{\text {wasteheat }}$ is the heat input from the waste heat energy.

\subsection{Numerical simulation results}

After the effects of heat transfer from the channels a large thermal boundary layer can be seen in the collector air domain illustrated in fig. 8 .

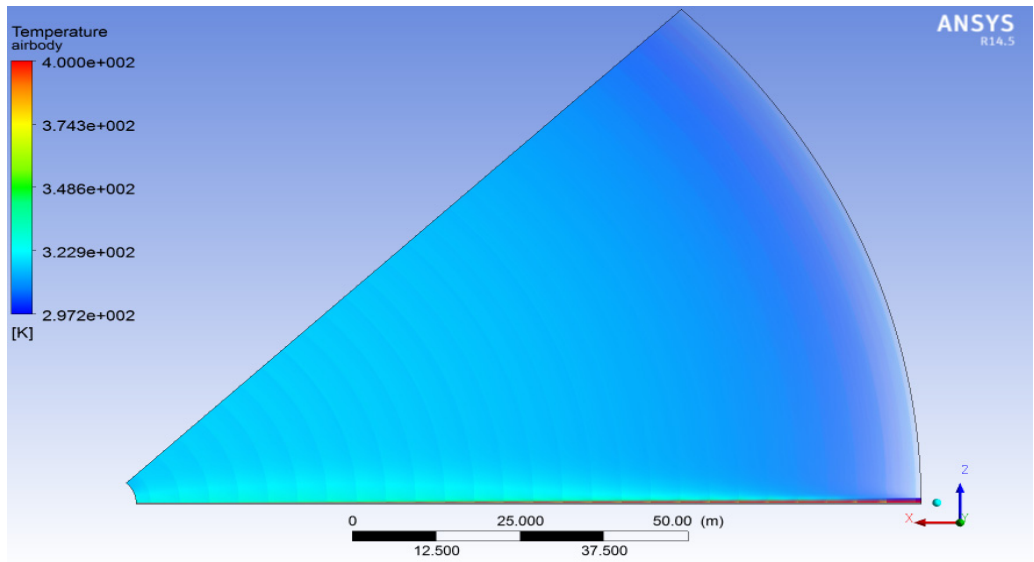

Figure 8: $\quad$ Temperature profile of collector air (top view). 
The velocity streamlines for the collector air flow have some swirls near the channel walls, which is due to the turbulence and duct flow. Fig. 9 describes the flow pattern.

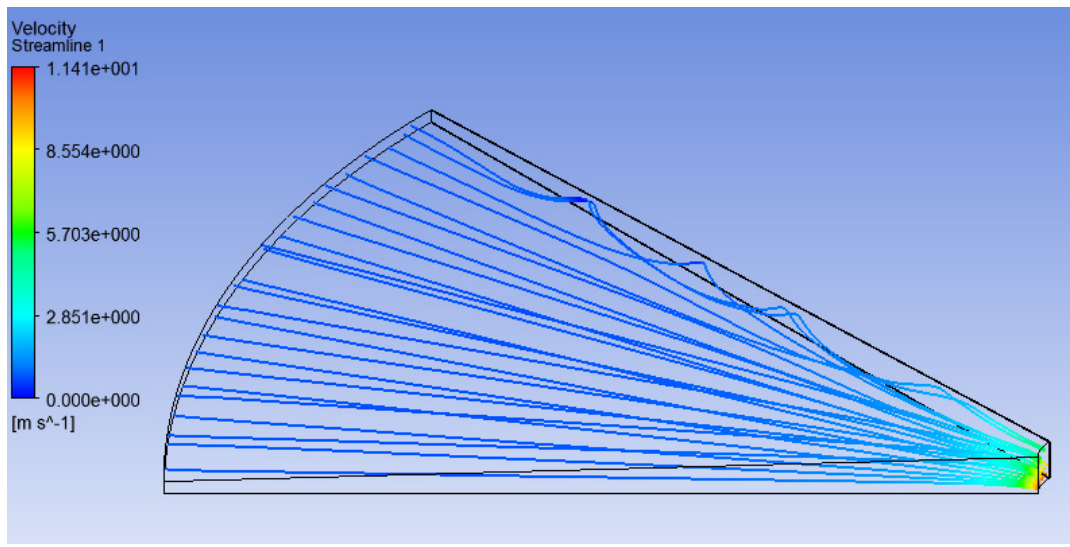

Figure 9: Flow pattern of collector air represented by streamlines.

\section{Conclusion}

This study is representing analysis of newly proposed approach for enabling the continuous day and night operation of SCPP system. Simulation results have shown considerable enhancement in the CGPP performance. The output power is increased by $24 \%$ and the efficiency increased by $19.4 \%$.

Just like conventional plants, this method of generating standby electricity from SCPP can be implemented well near any plant or factory releasing extra heat in the atmosphere. This helps to minimize the global warming since waste energy is made to be utilized with SCPP system.

\section{Acknowledgements}

The authors express gratitude to the Universiti Teknologi PETRONAS, UTP for the technical and financial support to present the work in the Sustainable City 2013 conference. The main author acknowledges UTP for sponsoring his MSc under the Graduate Assistance, GA scheme.

\section{References}

[1] Roozbeh, S., Majid, A. and Behzad, H., Modelling and numerical simulation of solar chimney power plants. Journal of Solar Energy, 85, pp. 829-838, 2011. 
[2] Tingzhen, M., Guoliang, X., Yuan, P., Fanlong, M. and Cheng, Z., Numerical analysis of flow and heat transfer characteristics in solar chimney power plants with energy storage layer, Journal of Energy Conversion and Management, 49, pp. 178-185, 2010.

[3] Dos Santos Bernardes, M.A., Von Backström, T.W. and Kröger, D.G. Analysis of some available heat transfer coefficients applicable to solar chimney power plant collectors, Journal of Solar Energy, 83, pp. 264-275, 2009.

[4] Jiakuan, Y., Xinping, Z., Bo, X., and Guoxiang, H., Simulation of a pilot solar chimney thermal power generating equipment, Journal of Renewable Energy, 32, pp. 1637-1644, 2006.

[5] Kreetz, H., Theoretische Untersuchungen und Auslegung eines temporären Wasserspeichers für das Aufwindkraftwerk, diploma thesis, Technical University Berlin, 1997.

[6] Al-Kayiem, H.H., Sing, C.Y., and Yin, K.Y., Numerical simulation of solar chimney integrated with exhaust of thermal power plant, Chapter in the special session on enhanced heat transfer, book title: Advanced Computational Methods and Experiments in Heat Transfer XII, WIT transaction of Engineering (ISSN: 1743-3533), WITpress, UK, 2012.

[7] Chikere, A.O., Al-Kayiem, H.H., and Abdul Karim, Z.A., Review on the Enhancement Techniques and Introduction of an Alternate Enhancement Technique of Solar Chimney Power Plant, Journal of Applied Sciences 11(11), pp. 1877-1884, 2011.

[8] HuiLan, H., Hua, Z., Yi, H., and Feng, L., Simulation calculation on solar chimney power plant system, Proc. of International Conference on Power Engineering, Hanzhou, China, pp. 1158-1161, 2007.

[9] Azeemuddin, Al-Kayiem H.H., and Gilani, S.I. Simulation of solar chimney power plant with an external heat source, Proc. of the $4^{\text {th }}$ International Conference on Energy and Environment, published in IOP conference series: Earth and Environmental Science, 16, 2013.

[10] Industrial Gas Turbines, 2012, SIEMENS catalog, www.siemens. com/energy 